\title{
The Effect of Different Types and Gelatin Concentrations on Ice Cream Quality
}

\author{
Diah Lestari Ayudiarti ${ }^{*}$, Suryanti, and Devi Ambarwaty Oktavia \\ Research and Development Center for Marine and Fisheries Product Processing and Biotecnology
}

\begin{abstract}
Gelatin is a polymer of amino acids found in collagen in bone tissue and animal skin. It is commonly used gelatin as stabilizer on an ice cream. Research on the effect of different types and gelatin concentrations on ice cream quality has been done. Types of gelatin Types of gelatin were used are commercial gelatin and fish gelatin. Ice cream were made by adding commercial and fish skin gelatin at concentration $0.1 \%$; $0.2 \% ; 0.3 \% ; 0.4 \%$ and $0.5 \%$. Overrun, total solid, melting run and sensory evaluation were observed as quality parameters of ice cream. Based on sensory evaluation, panelists preferred the taste of ice cream using additional $0.1 \%$ fish gelatin because it has soft texture than others. The result showed that ice cream with additional $0.1 \%$ fish gelatin had $30.63 \%$ overrun, $40.77 \%$ total solid and $197 \mathrm{~s} / \mathrm{g}$ melting run.
\end{abstract}

\section{Introduction}

Ice cream is a frozen processed product which is combination of milk, sweetener, stabilizer, emulsifier and flavoring [14]. Ice cream contains more than 10 percent of fat, both animal and vegetable fats. Commonly sources of fat are liquid cream, frozen cream, condensed milk, butter and skim milk. The fat content in ice cream can soften the texture of ice cream by reducing the formation of ice crystals during freezing and weakening the air cavity lamella so as to minimize the development of ice cream [4]. The use of fat in this process can cause the dough to be less stable. Because fat globules tend to separate and form a layer on the top of the dough. Separation of fat globules can be avoided by adding stabilizers and emulsifiers [12]. Stabilizers are used to bind water, to reduce the amount of free water, increase the viscosity of ice cream and minimize the formation of ice crystals so the ice cream texture is softer [15]. The stabilizer used in the ice cream mixture is $0.1-0.5 \%$ [7]. Ice cream stabilizers commonly used are gelatin, guar gum, locust gum, alginate, carrageenan, pectin, CMC and crystalline micro cellulose [14].

Gelatin is a polymer of amino acids found in collagen in bone tissue and animal skin [12]. Proline and hydroxyproline contained in gelatin function as a hydrophilic group of oil-in-water emulsions [12]. Gelatin dissolves in $71,1^{\circ} \mathrm{C}$ temperature [8]. Heat will open bonds to the gelatin molecule and the liquid which is initially free to flow becomes trapped in the molecular structure of the gelatin so that the solution becomes thick [20].

Many food industries in Indonesia use gelatin as an additive material. They usually obtain gelatin through import, because in Indonesia there are still very few companies that

\footnotetext{
*Corresponding author: diah_stari@yahoo.co.id
} 
produce gelatin. Usually commercial gelatin was made from bone and cow or pork skin, because of that, imported gelatin is still questionable of halal status. However, gelatin also can be made from skin or fish bones. Fish gelatin gelatin is not at risk of containing Bovine Spongiform Encephalopathy and meets halal criteria so that it is safe for consumption by Muslims [18]. Fish gelatin can replace gelatin from cows or pigs [13]. Gelatin can be used as an emulsifier, binder, foaming agent and clarifier. That's why gelatin is widely used in the food, pharmaceutical, cosmetics and photography industries [22]. In previous research, we have been produced gelatin from tuna skin, but we still do not know, does fish gelatin we produced has similar characteristics with commercial gelatin when it was added to food. this research was made to compare the ice cream quality with addition commercial and fish gelatin.

\section{Materials and methods}

\subsection{Materials}

In this research, we used two kinds of gelatin which are commercial gelatin and fish gelatin. Commercial gelatin was bought from cake shop in the market and was made from cow bones. Fish gelatin was made in a previous research which was extracted from tuna skin using the acid method. Based on both gelatin analysis, commercial gelatin has $5.9 \mathrm{cPs}$ viscosity and 282.58 gbloom gel strength while fish gelatin has a viscosity of $6.3 \mathrm{cPs}$ and a gel strength of 302.8 gbloom. Other ingredients that were needed to make ice cream formulations were $60 \mathrm{~g}$ butter, $300 \mathrm{~g}$ full cream milk, $60 \mathrm{~g}$ low-fat milk, $60 \mathrm{~g}$ sugar and water until the total ingredients reached $500 \mathrm{~g}$.

\subsection{Methods}

Ice cream were made by blending all the ingredients i.e. butter, full cream milk, low fat milk sugar and water. After it blended than added gelatin into the ice cream mixture. The concentration of gelatin used was $0.1 ; 0.2 ; 0.3 ; 0.4$ and $0.5 \%$ for each kinds of gelatin. Ice cream mixture was put in an ice cream maker for 30 minutes, then the ice cream was stored in a freezer at $-30^{\circ} \mathrm{C}$ for 24 hours. After 24 hours, it was analyzed overrun, total solid, melting run and sensory.

Research on making ice cream with the addition types and gelatin concentrations using a randomized complete design with three replications. The overrun, total solid and melting run data were analyzed using multivariate test and for sensory analysis were analyzed using the Kruskall Wallis test.

\section{Results and discussion}

The addition of gelatin in ice cream, either commercial gelatin or fish gelatin gives a soft texture to the ice cream. Observations descriptively stated that ice cream added with commercial gelatin had no significant difference when compared to the quality of ice cream added with fish gelatin. Trend analysis resulted that ice cream with the addition of fish gelatin have the same characteristics with ice cream added commercial gelatin. Multivariate analysis revealed that concentrations gelatin significantly influenced the overrun of ice cream. It also showed that gelatin types influenced the ice cream melting run. According of sensory analysis, panelists like ice cream with the addition of $0.1 \%$ fish gelatin. 


\subsection{Overrun}

Overrun is a measurement the amount of air in ice cream or the ratio between gas volumes to liquid volume [5]. The value of the results of the overrun analysis in ice cream can be seen in Figure 1. The results of the analysis of overrun ice cream ranged from $15.33 \%$ to $30.63 \%$. The highest value of overrun was showed by ice cream that added with $0.1 \%$ commercial gelatin and the lowest overrun value was showed by ice cream using $0.5 \%$ fish gelatin.

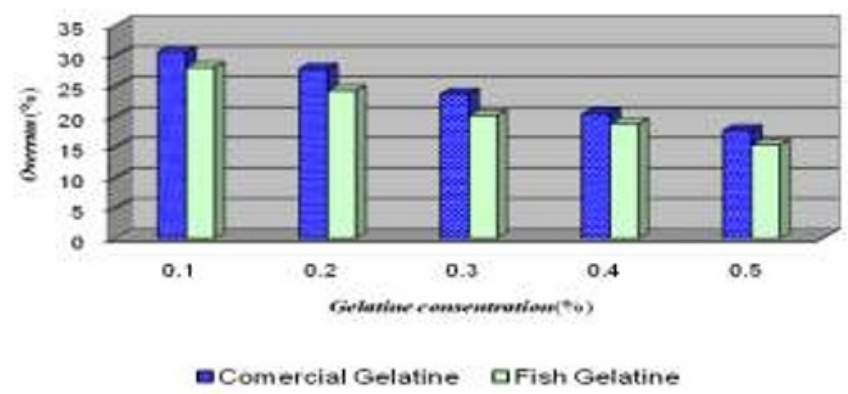

Fig. 1. Overrun of ice cream graphic

The analysis showed that addition gelatin concentration will decreased ice cream overrun. The multivariate test showed that concentrations gelatin significantly influenced the ice cream overrun. More higher gelatin concentration were added to the ice cream it will thickened the ice cream mixture, The stabilizer increases the thickness of the dough by forming matrix gel and hold the dispersed liquid phase [6].

More thicker the dough will caused the surface tension to be even higher and it caused the air become more difficult to penetrate into the dough so the overrun ice cream will be lower [2]. Because the fish gelatin viscosity is higher than commercial gelatin, so the ice cream mixture with the addition of fish gelatin will be thicker and had lower overrun than ice cream with commercial gelatin. Results reported by [11] stated that use gelatin as a stabilizer in ice cream can gave higher overrun compared to CMC.

\subsection{Total solid}

The results of the analysis of total ice cream solids ranged from $37.46 \%$ to $40.77 \%$. The highest value is owned by ice cream using gelatin tuna skin with a concentration of $0.1 \%$ and the lowest value is owned by ice cream using commercial gelatin with a concentration of $0.4 \%$. The results of analysis of total solids in ice cream can be seen in Figure 2. 


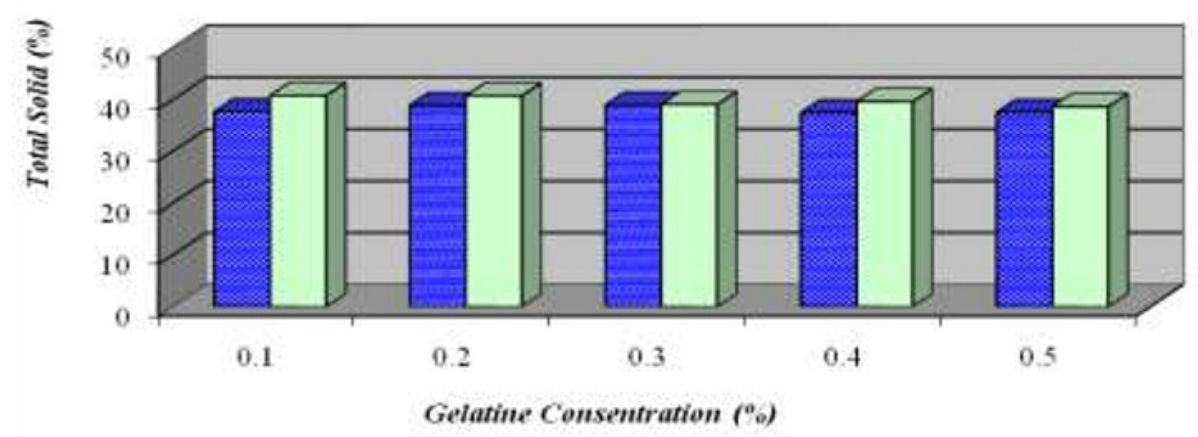

-Comercial Gelatine afish Gelatine

Fig. 2. Total solid of ice cream graphic

The analysis showed that addition gelatin concentration will decreased total solid. The multivariate test showed that type and gelatin concentrations were not influenced the total solid of ice cream. Total solids are usually influenced by the amount of solid that added in ice cream mixture. Full cream milk, sugar and skim milk have high total solids [23]. The solid ingredient in the ice cream formulation had the same composition, so the total solids in ice cream will not be different for each formulation. [17] stated that premium ice cream quality usually have the total solids value ranges from $38-40 \%$, because it contains high fat and milk. Based on that, this ice cream formulations were included premium ice cream.

\subsection{Melting run}

Melting run is the time required for the ice cream to melt perfectly. The results of the analysis of the melting run of ice cream range from 131s/g $-226 \mathrm{~s} / \mathrm{g}$. The highest melting run is showed by ice cream which used $0.5 \%$ fish gelatin and the lowest melting run was showed by ice cream with $0.1 \%$ commercial gelatin. The average value of the speed analysis of melting ice cream can be seen in Figure 3.

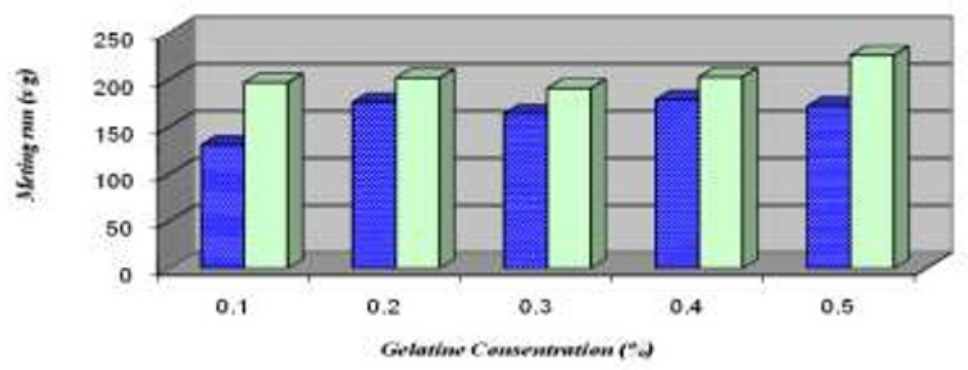

aComercial Gelatine $\quad$ Fish Gelatine

Fig. 3. Melting run of ice cream graphic 
The melting speed of this ice cream is very much determined by the total solids, the texture of the ice cream and the intensity of sweetness. Ice cream that has a low total solids will cause the texture of the ice cream to be rough, causing the ice cream to melt easily [16]. The multivariate test showed that types gelatin significantly influenced the ice cream melting run. Ice cream that uses gelatin as a stabilizer will melt more easily.

Ice cream with commercial gelatin had higher melting run than ice cream with fish gelatin. Because the commercial gelatin had lower viscosity and gel strength so when it homogenized with ice cream dough, it trapped air higher than fish gelatin. So when it kept in room temperature, the air inside the dough will heat up faster and it make ice cream mixture it was easily to melt [20]. When gelatin interacts with water, water molecules will be trapped in the amino acid chain which will form a cross link between the carboxyl group of the disulfide salt and the carboxyl group of amino acids [10]. Gelatin formed gel involves only secondary bonds rather than covalent bonds, so it make gelatin easily to melt than other stabilizer i.e. hydrocolloids (carrageenan, gum arabic) [9].

\subsection{Sensory Evaluation}

Panelist assessment stated that the type and concentration of gelatin only affected the texture of ice cream and did not affect the color, aroma and taste of ice cream.

\subsection{Color}

The color parameters showed that the highest score was showed by ice cream using $0.4 \%$ fish gelatin and $0.5 \%$ commercial gelatin while the lowest score was showed by ice cream using $0.5 \%$ fish gelatin. The average color score of ice creams can be seen in Figure 4.

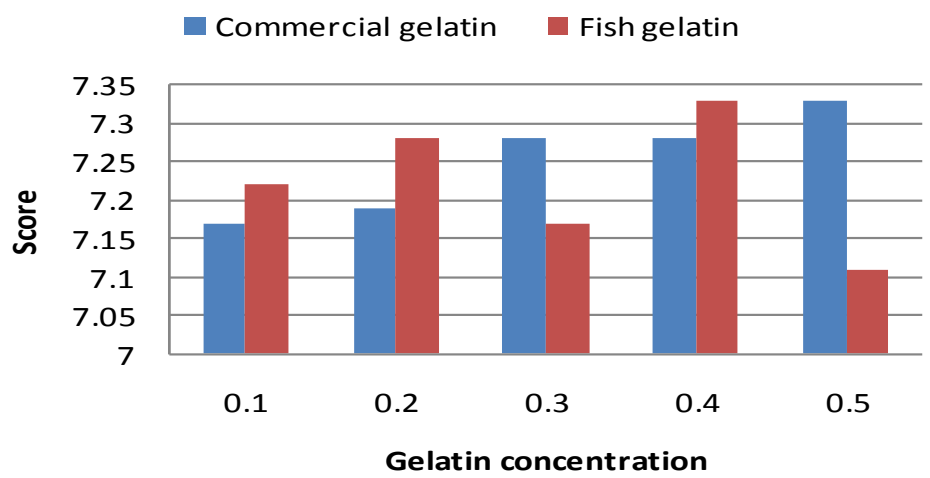

Fig. 4. Color attribute of ice cream

The results of Kruskall Wallis analysis of color parameters showed there were no significant difference $(\mathrm{p}<0.05)$ between treatments. Panelists stated that the color of ice cream using commercial gelatin and fish gelatin had yellowish color. The gelatin addition did not affected the color of the ice cream, it were more affected by the addition of butter. This is indicated that the yellowish color where came from butter color. 


\subsection{Odor}

The results of odor parameters showed that the highest odor score was showed from ice cream using $0.3 \%$ commercial gelatin while the lowest score was showed by ice cream using $0.3 \%$ fish gelatin. The value of the ice cream odor can be seen in Figure 5.

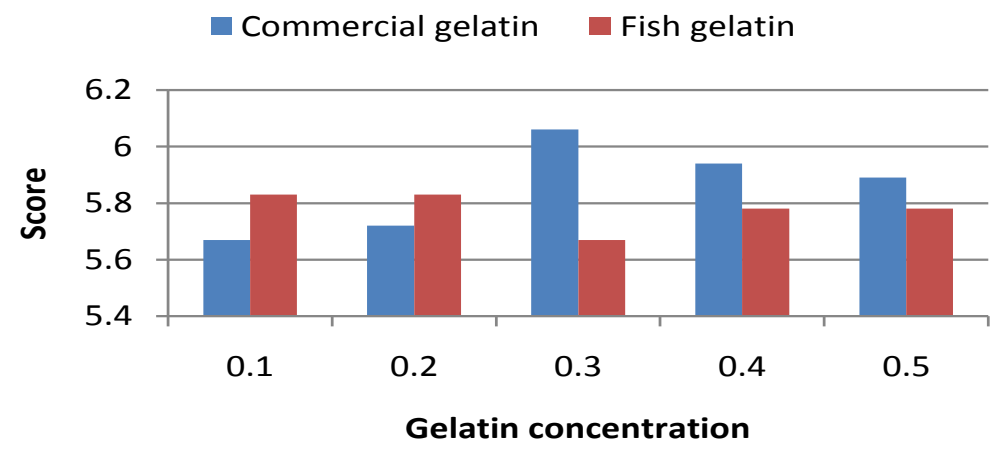

Fig. 5. Odor attribute of ice cream

The results of Kruskall Wallis analysis showed there were no significant difference ( $\mathrm{p}<0.05$ ) between treatments. Panelists stated that ice cream with $0.3 \%$ fish gelatin had a little fishy odor than other ice cream with fish gelatin but it was not disturbing because the milk odor is stronger than the fishy odor.

\subsection{Taste}

The taste parameters showed that the highest taste score was indicated by ice cream using $0.1 \%$ tuna gelatin while the lowest score was indicated by ice cream using $0.3 \%$ gelatin tuna. The average value of the panelist analysis of ice cream flavor can be seen in Figure 6.

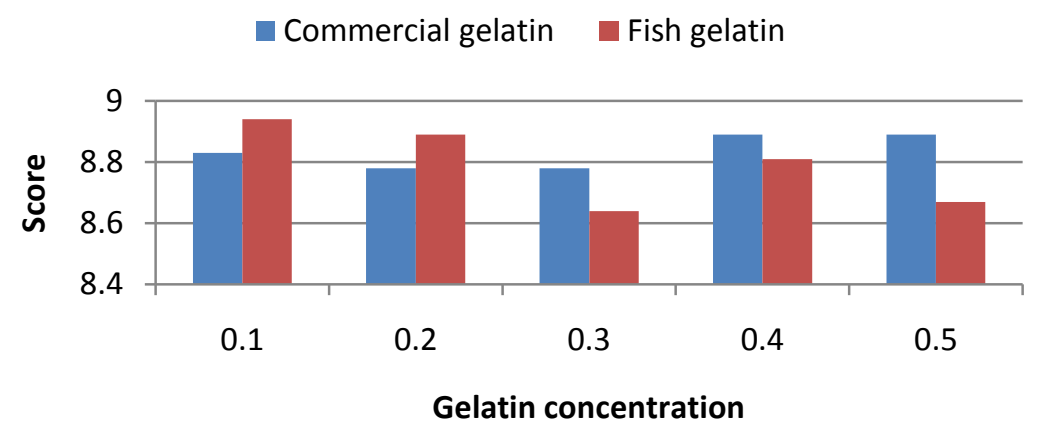

Fig. 6. Taste attribut of ice cream

The results of Kruskall Wallis analysis of taste parameters showed no significant difference $(\mathrm{p}<0.05)$ between treatments. Panelists stated that the addition of gelatin concentration did not affect the taste of ice cream even though what was added was commercial gelatin and fish gelatin. The gelatin or fishy taste on the ice cream were not detected because it were covered with sweetness from sugar and the savory taste of milk. 


\subsection{Texture}

Texture parameters showed that the highest texture score was indicated by ice cream using $0.5 \%$ tuna gelatin while the lowest score was indicated by ice cream using $0.1 \%$ commercial gelatin. The average value of the panelist analysis of the texture of ice cream can be seen in Figure 7.

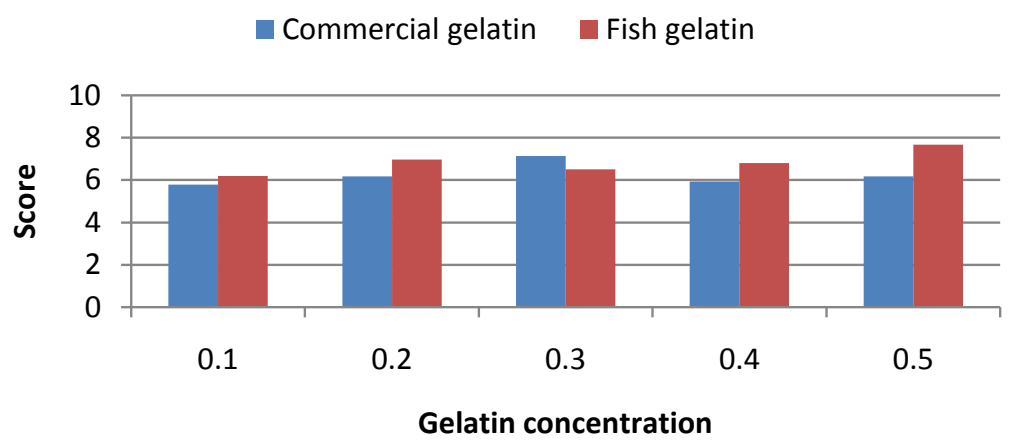

Fig. 7. Texture attribute of ice cream

The results of Kruskall Wallis analysis showed a significant difference $(p<0.05)$ between treatments. The addition of gelatin concentration was tend to increase the softness of ice texture. The texture of ice cream is also influenced by the type of gelatin used. The greater the viscosity value of the gelatin used, the softer the texture of the ice cream produced [3]. From gelatin characteristic, it showed that fish gelatin had higher viscosity and gel strength than commercial gelatin.

\section{Conclusion}

There is no different quality between both of Ice cream, more higher concentration of gelatin will be decreased the overrun and melting run also soften the ice cream texture because the viscosity was increase. Based on sensory evaluation, panelists preferred the taste of ice cream using additional $0.1 \%$ fish gelatin because it has soft texture than others. The result showed that ice cream with additional $0,1 \%$ fish gelatin had $30,63 \%$ overrun, $40,77 \%$ total solid and $197 \mathrm{~s} / \mathrm{g}$ melting run.

\section{References}

1. AOAC. Official methods of analysis. 15th Ed. (AOAC Inc. Arlington, Vigrinia, 2005).

2. Arbuckle, W.S. Ice Cream (The AVI Publishing Company Inc., Wesport, Connecticut, 1981).

3. Cahyadi, W. Analysis and Health Aspects of Food Additives (Earth Literacy, Jakarta, 2005).

4. Campbell, J.R. and Marshall, R.T. The Science of Providing Milk for Men (Mc. GrawHill Book Co., Inc., New York, 1975).

5. Clarke C. The Science of Ice Cream (London (UK), The Royal Society of Chemistry, 2004).

6. Dahlberg, P.H. A. J. Food Science 4(4), 335-347 (2005)

7. Eckles, E.H, Combs, W.B and Macy, H. Milk and Milk Products (Tata Mc. Graw-Hill Publishing Co., Ltd., Bombay, 1984). 
8. Glicksman, M. Gum Technology in Food Industry (Academic Press, New York, 1969).

9. Glicksman, M. Food Hydrocolloids I (CRC Press Inc., Boca Raton Florida, 1983a).

10. Glicksman, M. Food Hydrocolloids II (CRC Press Inc., Boca Raton Florida, 1983b).

11. Hartatie SH. GAMMA 7(1), 20 - 26 (2011).

12. Imeson, A. Gelatin. In A. Imeson (Eds.) Thickening and Gelling Agents for Food. (Chapman and Hall, New York, 1992).

13. Kim, S. and Mendis, E. Food Research International 39, 383-393 (2006).

14. Marshall, R.T. and W.S. Arbuckle. Ice Cream (Chapman and Hall, New York, 2000).

15. Murtaza, M.A, Mueen, U. D, Huma, N., Shabbir, M. A, and Mahmood, S. International Journal of Agriculture and Biology 6 (1): 65-67 (2004).

16. Nelson, J.A. and Trout, G.M. Judging Diary Products (The Olsen Publishing Company, Wisconsin, 1951).

17. Regand, A. and Goff, H. D. J. Dairy Sci. 85: 2722-2732 (2002).

18. Rustad, T. Electronic Journal of Environmental, Agricultural and Food Chemistry 2, 458-463 (2003).

19. Soekarto, T. Organoleptic Assessment for the Food and Agricultural Products Industry (Bharata, Yogyakarta, 1981)

20. Stainsby, G. The Physical Chemistry of Gelatin in Solution. In A.G. Ward and A. Courts (Ed.) The Science and Technology of Gelatin (Academic Press, New York, 1977).

21. Swaisgood, H.E. Characteristic of Edible Fluids of Animal Origin: Milk. In O.R Fennema (ed). Principles of Food Chemistry (Marcell Dekker, Inc., New York. P.791$825,1985)$

22. Wasswa, J., Tang, J. and Gu, X. Food Reviews International 23,159-174 (2007).

23. Zahro C and Nisa FC. Jurnal Pangan dan Agroindustri 3(4), 1481-1491 (2015). 